\title{
KINETIKA REAKSI ESTERIFIKASI MINYAK BIJI KAPUK PADA PEMBUATAN BIODIESEL
}

\author{
Siti Salamah ${ }^{1}$ \\ ${ }^{1}$ Program Studi Teknik Kimia FTI UAD, Kampus III, Jl Supomo, Janturan, Warungboto, Yogyakarta 55164 \\ Email: sitisalamah@che.uad.ac.id
}

\begin{abstract}
Biodiesel is one of the best solutions to overcomethe reduction of oil reserves by utilizing plant oils are converted into fuel.Kapok seed is one of the potential sources of raw materials that can be taken to be used as biodiesel. For the manufacture of biodiesel on a large scale is necessary to design the reactor, the reactor needs to design the data of reaction kinetics.

This reaserch was conducted to determine the rate of reaction of biodiesel production. The process was by making kapok seed oil and analyzed the content of FFA, if FFA $<2$ then the esterification process is done.150 ml oil inserted in three neck flask and heated to temperature of $50{ }^{\circ} \mathrm{C}$ with water bath. While waiting for heating, $57 \mathrm{ml}$ of techinical methanol $96 \%$ was mixed with 1.25 grams $\mathrm{KOH}$ p.a and stirred for 60 minutes, then either mixing the solution with the oil heated with a water bath. The reaction temperature was maintained at $50^{\circ} \mathrm{C}$ with stirring speed of $600 \mathrm{rpm}$ for 60 minutes. Inserting the solution into a separator funnel and left for 24 hours to form 2 layers.Separating the two layers.The top layer wasbiodiesel and the bottom layer was glycerol.Repeating step by step above with the variation of time 60, 75, 90, 105 and 120 minutes. For reaction temperature variable, the process carried out at temperatures $40{ }^{\circ} \mathrm{C}, 50^{\circ} \mathrm{C}$, $70{ }^{\circ} \mathrm{C}$ and $90{ }^{\circ} \mathrm{C}$.

The results of this reaserch were the water content of kapok seed is 4,07 \% and FFA valuewas 4,8\% after lowered 1,56\%.Transesterification reaction conditions of oil and methanol mole ratio of $1: 3$, with the stirrer rotation speed of $600 \mathrm{rpm}$ for 105 minutes and the reaction temperature of $90^{\circ} \mathrm{C}$ gave the conversion of $0.916 \mathrm{~mol}$ (\%).Transesterification reaction of kapok seed oil into biodiesel follows the first order reaction.The results of the analysis of biodiesel and the heat test, may indicate that it meets the criteria specified in the benchmark Indonesian Biodiesel Quality Standards (RSNI EB 020 551).
\end{abstract}

Keywords : Reaction kinetics, esterification, kapok seed, oil, and biodiesel

\section{Pendahuluan}

Peta energi dalam negeri menunjukkan hal yang tidak jauh berbeda. Kebutuhan Bahan Bakar Minyak (BBM) pada tahun 2008 mencapai 215 juta liter per hari, sedang produksinya baru mencapai 178 juta liter per hari, untuk memenuhi kebutuhan masih harus di impor dari Negara lain. Melalui Peraturan Presiden nomer 5 tahun 2006 tentang kebijakan energi nasional dan Intruksi Presiden nomor 1 tahun 2006 tentang penyediaan dan pemanfaatan bahan bakar nabati (biofuel) sebagai bahan bakar lain[1]. Menurut ROAD MAP pengembangan Biofuel, pemerintah merencanakan pemamfaatan biodiesel sebesar $20 \%$ komsumsi solar 10,22 juta kilo liter[2]. Oleh karena itu penelitian-penelitian tentang biodiesel cukup prospektif.

Biodiesel merupakan bahan bakar alternatif dari bahan mentah terbaharui (renewable) selain bahan bakar diesel dari minyak bumi. Biodiesel tersusun dari berbagai macam ester asam lemak yang dapat diproduksi dari minyak-minyak tumbuhan seperti minyak sawit (palm oil), minyak kelapa, minyak jarak pagar, minyak biji kapok/randu [3].

Beberapa penelitian tentang pembuatan biodiesel dari minyak nabati antara lain dilakukan oleh [4], penelitian ini tentang transesterifikasi minyak biji kapas menggunakan katalis heterogen padatan basa. [5] telah meneliti pemanfaatan biji kapuk yang merupakan limbah industri kapuk untuk pembuatan bahan bakar alternatif biodiesel. Kinetika reaksi Etanolisis minyak jarak dengan katalisator $\mathrm{NaOH}$ dan penambahan garam dapur pada tekanan di atas satu atm telah dilakukan [6].Penelitian kinetika reaksi 
pembuatan biodiesel dengan esterifikasi asam lemak dengan katalis neobium okside telah diteliti oleh[7]. Dalam penelitian ini akan ditentukan kinetika reaksi pembuatan biodiesel dari minyak biji kapuk dengan pross tranesterifikasi dengan katalis $\mathrm{KOH}$.

Biodiesel dapat dibuat dari minyak nabati dengan proses Esterifikasi.Trans esterifikasi atau sering disebut reaksi alkoholisis adalah reaksi antara trigliserida ( yg berasal dari minyak nabati ).Dari penelitianpenelitian sebelumnya bahwa minyak biji kapuk dapat dibuat biodiesel.Untuk merancang reaktor pembuatan biodiesel dari minyak biji kapuk, diperlukan data kinetika reaksi antara lain bagaimana bentuk persamaan kecepatan reaksinya dan berapa nilai konstanta kecepatan reaksinya, kemudian dari data kinetika maupun data ter-modinamikanya, dapat ditentukan ukuran reaktor dan kondisi operasi yang baik untuk reaksi tersebut. Karena biodiesel dari minyak biji kapuk ini sangat potensial untuk dikembangkan dan diproduksi dalam skala industri menengah / koperasi atau skala besar, terutama untuk home industri kapuk. Dari penelitian ini diharapkan dapat memberikan pengetahuan kinetika reaksi biodiesel dari minyak biji kapuk sehingga dapat ditentukan ukuran reaktor untuk industri biodiesel skala industri kecil khususnya bagi industri kapuk di daerah Tegal kembang Imogiri Bantul Yogyakarta agar limbah industri kapuk dapat dimanfaatkan.

\section{Metodologi}

\section{Alat Penelitian}

Alat pres minyak; alat proses transesterifikasi ; rangkaian alat destilasi ; alat titrasi, timbangan analitis ,Kromatografi Gas Spektramassa (GC-MS) SHIMADZU

\section{Bahan :}

Minyak biji kapuk (diperoleh dari hasil pressing biji kapuk; Metanol;Alkohol 96\%; KOH. Aquadest.; Indikator Phenolfthalein dan kertas saring.

\section{Cara Penelitian}

\section{Uji FFA (Free Fatty Acid) atau Asam Lemak Bebas}

Minyak yang didapat diuji kandungan asam lemak tak jenuhnya dengan Alat GC- MS di Jurusan laboratorium Kimia Organik, Fakultas MIPA, Universitas Gadjah Mada. Selanjutnya melakukan analisis FFA (free fatty acid) terhadap minyak biji kapuk dengan metode titrasi. Titrasi dilakukan dengan menggunakan larutan standar $\mathrm{KOH} \mathrm{0,1} \mathrm{N} \mathrm{dan} 3$ tetes indikator phenolfthalein sampai terjadi perubahan warna (merah muda). Titrasi dilakukan sebanyak 3 kali.FFA ditentukan dengan cara sebagai berikut :

Minyak atau lemak sebanyak 10-20 gram ditambah $50 \mathrm{ml}$ alkohol netral 95\% kemudian dipanaskan 10 menit dalam penangas air sambil diaduk dan ditutup pendingin balik. Alkohol berfungsi untuk melarutkan asam lemak. Setelah didinginkan kemudian dititrasi dengan $\mathrm{KOH}$ 0,1 N menggunakan indikator phenolphtalein sampai tepat berwarna merah jambu.

$$
\begin{aligned}
& \text { Kadar asam lemak bebas (\%FFA) }=\frac{\mathrm{ml} \mathrm{KOH} \mathrm{x} \mathrm{N} \mathrm{KOH} \mathrm{x} \mathrm{Mr}}{\text { Bobot contoh (gram) x } 10} \\
& \text { Keterangan : } \\
& \mathrm{Mr}=\text { Molekul relatif asam lemak yang paling banyak dalam minyak. }
\end{aligned}
$$

\section{Proses pembuatan biodiesel}

\section{a. Pembuatan Biodiesel dengan Variasi Waktu Reaksi}

Sebanyak $150 \mathrm{ml}$ minyak dimasukkan dalam labu leher tiga dan dipanaskan hingga mencapai suhu $50{ }^{\circ} \mathrm{C}$ dengan water bath. Sambil menuggu pemanasan, sebanyak $57 \mathrm{ml}$ methanol teknis $96 \%$ dicampur dengan 1,25 gram $\mathrm{KOH}$ p.a dan diaduk selama 5 menit. Kemudian mencampur larutan tersebut dengan minyak di dalam labu leher tiga yang dipanaskan dengan water bath. Dimana suhu reaksi dijaga $60^{\circ} \mathrm{C}$ dengan kecepatan pengadukan $600 \mathrm{rpm}$ selama 60 menit. Memasukkan larutan ke 
dalam corong pemisah kemudian biarkan selama 24 jam sampai terbentuk 2 lapisan.Memisahkan lapisan atas adalah metil ester (biodiesel) dan lapisan bawah adalah gliserol. Mengulangi langkah langkah di atas dengan variasi waktu reaksi yang berbeda-beda ( 60, 75, 90, 105 dan 120 menit).

\section{b. Pembuatan Biodiesel dengan Variasi Suhu Reaksi}

Sebanyak $150 \mathrm{ml}$ minyak dimasukkan dalam labu leher tiga dan dipanaskan hingga mencapai suhu $50{ }^{\circ} \mathrm{C}$ dengan water bath. Sambil menuggu pemanasan, sebanyak $50 \mathrm{ml}$ methanol teknis $96 \%$ dicampur dengan 1,25 gram $\mathrm{KOH}$ p.a dan diaduk selama 60 menit, selanjutnya mencampur larutan tersebut dengan minyak di dalam labu leher tiga yang dipanaskan. Suhu reaksi dijaga $60^{\circ} \mathrm{C}$ dengan kecepatan pengadukan 600 rpm selama 60 menit. Memasukkan larutan ke dalam corong pemisah kemudian dibiarkan selama 24 jam sampai terbentuk 2 lapisan. Memisahkan antara kedua lapisan tersebut. Lapisan atas adalah metil ester (biodiesel) dan lapisan bawah adalah gliserol. Mengulangi langkah - langkah di atas dengan variasi suhu reaksi yang berbeda-beda yakni $\left(40^{\circ} \mathrm{C}, 70^{\circ} \mathrm{C}\right.$ dan $\left.90^{\circ} \mathrm{C}\right)$.

\section{c. Analisis Hasil}

Biodiesel yang didapat, dianalisis dengan GC dan GC-MS di laboratorium Kimia Organik FMIPA UGM . Analisis sifat biodiesel di laboraturium Teknologi Minyak Bumi, Jurusan Teknik Kimia, (meliputi Analisis Specific Gravity ,Viscosity Kinematic, Cloud Point, ${ }^{0} \mathrm{C}$, Flash Point ${ }^{0} \mathrm{C}$ ). Hasil analisis nilainya dibandingkan dengan Nilai standar biodiesel yang ditetapkan oleh Pemerintah.Apakah sudah memenuhi kriteria atau belum.Jika nilai -nilai kualitas biodiesel sudah sesuai maka biodiesel yang diperoleh layak digunakan.

\section{Hasil dan Pembahasan}

\section{Analisis minyak biji kapuk}

Minyak kapuk hasil pressing berwarna kuning kecoklatan kemudian dianalisis kandungan asam lemaknya dengan alat GC-MS di laboratorium Kimia Organik,FMIPA UGM Yogyakarta. Dari data GC-MS diketahui bahwa asam lemak paling dominan adalah Asam linoleat sebanyak 50,89\% diikuti dengan kandungan asam lemak lainnya sebesar 49,11\% seperti asam palmitat dan asam oleat .

Minyak biji kapuk yang diperoleh kemudian diujikan karekteristiknya di Laboratorium Teknologi Minyak Bumi, Gas dan Batu bara, Jurusan Teknik Kimia, Fakultas Teknik, UGM. Hasil pemeriksaan contoh minyak biji kapuk terdapat pada Tabel 1.

Tabel 1. Hasil pemeriksaan contoh minyak biji kapuk

\begin{tabular}{|l|l|c|c|}
\hline No. & \multicolumn{1}{|c|}{ Jenis Pemeriksaan } & $\begin{array}{c}\text { Hasil Pemeriksaan } \\
\text { Minyak Biji Kapuk }\end{array}$ & $\begin{array}{c}\text { Metode } \\
\text { Pemeriksaan }\end{array}$ \\
\hline 1. & Density at $15^{0} \mathrm{C}, \mathrm{g} / \mathrm{ml}$ & 0,9064 & ASTM D 1298 \\
\hline 2. & Viscosity kinematic at $40^{0} \mathrm{C}, \mathrm{mm}^{2} / \mathrm{s}$ & 38,09 & ASTM D 445 \\
\hline 3. & Flash Point P.M.C.C., ${ }^{0} \mathrm{C}$ & 264,5 & ASTM D 93 \\
\hline
\end{tabular}

Dari hasil tersebut di atas maka minyak biji kapuk layak digunakan untuk bahan baku pembuatan biodiesel.

\section{Kadar FFA Minyak Biji kapuk}

Dari hasil perhitungan diketahui bahwa kadar asam lemak bebas (\%FFA) sebesar 4,8486 \%. Minyak dengan kandungan FFA lebih besar dari 2\% tidak dapat langsung diolah menjadi biodiesel, melainkan harus diesterifikasi terlebih dahulu agar kandungan FFAnya lebih rendah dari 2\% [8]. Proses esterifikasi dilakukan dengan katalis asam seperti $\mathrm{H}_{2} \mathrm{SO}_{4}$. Oleh karena itu pada penelitian ini 
sebelum proses transesterifikasi dilakukan proses esterifikasi dengan katalisator $\mathrm{H}_{2} \mathrm{SO}_{4}$ (pekat) sebanyak $3 \mathrm{ml}$ dan terjadi penurunan kadar FFA minyak biji kapuk menjadi 1,56 \% .

\section{Kinetika reaksi Biodiesel}

\section{a. Pengaruh Waktu Reaksi}

Pengaruh waktu reaksi terhadap konversi dipelajari pada variasi waktu 60, 75, 90, 105 dan 120 menit. Pada variasi waktu, variabel lain yaitu suhu reaksi dibuat tetap pada $60{ }^{\circ} \mathrm{C}$.Digunakan suhu $60{ }^{\circ} \mathrm{C}$ karena penelitian sebelumnya merupakan suhu yang optimal untuk persen hasil biodiesel yang diperoleh [5].

Data konversi terhadap waktu pada suhu $60{ }^{\circ} \mathrm{C}$ dapat dilihat pada Tabel 2

Tabel 2. Hasil Biodiesel pada variabel waktu

\begin{tabular}{|l|c|c|c|c|c|}
\hline No. & $\begin{array}{c}\text { Variasi waktu } \\
\text { reaksi }\end{array}$ & $\begin{array}{c}\text { Volume } \\
\text { Minyak }\end{array}$ & $\begin{array}{c}\text { Volume } \\
\text { Methanol }\end{array}$ & $\begin{array}{c}\text { Volume } \\
\text { Biodiesel }\end{array}$ & $\begin{array}{c}\text { Konversi mol } \\
\text { (\%) }\end{array}$ \\
\hline 1. & 60 menit & $150 \mathrm{ml}$ & $57 \mathrm{ml}$ & $146 \mathrm{ml}$ & 0,8829 \\
\hline 2. & 75 menit & $150 \mathrm{ml}$ & $57 \mathrm{ml}$ & $144 \mathrm{ml}$ & 0,9028 \\
\hline 3 & 90 menit & $150 \mathrm{ml}$ & $57 \mathrm{ml}$ & $144 \mathrm{ml}$ & 0,9130 \\
\hline 4. & 105 menit & $150 \mathrm{ml}$ & $57 \mathrm{ml}$ & $144 \mathrm{ml}$ & 0,9160 \\
\hline 5 & 120 menit & $150 \mathrm{ml}$ & $57 \mathrm{ml}$ & $144 \mathrm{ml}$ & 0,9155 \\
\hline
\end{tabular}

Dari data di atas menunjukkan semakin lama waktu reaksi maka konversi semakin bertambah, konversi paling optimal pada waktu 105 menit, waktu reaksi yang lebih lama konversinya menurun meski relatif sedikit, hal ini kemungkinan disebabkan waktu 106 menit merupakan waktu saat dimana kesetimbangan reaksi transesterifikasi tercapai. Transesterifikasi merupakan reaksi yang reversible (bolak-balik) sehingga saat reaksi sudah mencapai kondisi optimum maka reaksi akan bergeser ke kiri dan akan memperkecil produk yang diperoleh.

Hal ini juga sejalan dengan yang diungkapkan Rosu [9] bahwa semakin lama waktu reaksi yang diberikan maka reaksi akan semakin berlangsung sempurna hingga sampai pada titik maksimum dan kemudian untuk waktu yang lebih lama lagi akan terjadi reaksi lain yaitu berupa reaksi hidrolisis ester.

Dari tabel 2, kemudian dihitung nilai tetapan reaksi (k) nya, diperoleh hasil seperti yang disajikan dalam Tabel 3 berikut :

Tabel 3. Harga k untuk variabel perubahan waktu reaksi

\begin{tabular}{|c|c|c|c|c|}
\hline No. & $\begin{array}{c}\text { Waktu reaksi, } \mathrm{t} \\
\text { (menit) }\end{array}$ & Konversi (Xa) & $\ln (1-\mathrm{Xa})$ & $\begin{array}{c}\mathrm{k} \\
\left.\mathrm{mol}^{-1} \cdot \mathrm{menit}^{-1}\right)\end{array}$ \\
\hline 1 & 60 & 0,883 & 2,145 & 0,126 \\
\hline 2 & 75 & 0,903 & 2,33 & 0,124 \\
\hline 3 & 90 & 0,913 & 2,441 & 0,116 \\
\hline 4 & 105 & 0,916 & 2,477 & 0,104 \\
\hline 5 & 120 & $0 ., 915$ & 2,471 & 0,090 \\
\hline
\end{tabular}


Chemica

Volume 1, Nomor 1, Juni 2014, 11-18

ISSN : 2355-8776

Hubungan antara $-\ln (1-\mathrm{Xa})$ dengan waktu reaksi (t) dapat dilihat pada Gambar 1 dan dengan regresi linier didapatkan persamaan matematis sebagai berikut :

$$
-\ln (1-X a)=5\left(10^{-3}\right) t+1,894
$$

Dengan demikian dapat disimpulkan bahwa reaksi transesterifikasi minyak biji kapuk dapat didekati dengan kinetika reaksi orde satu dengan nilai $\mathrm{k}=0,005\left(\right.$ menit $\left.^{-1}\right)$.

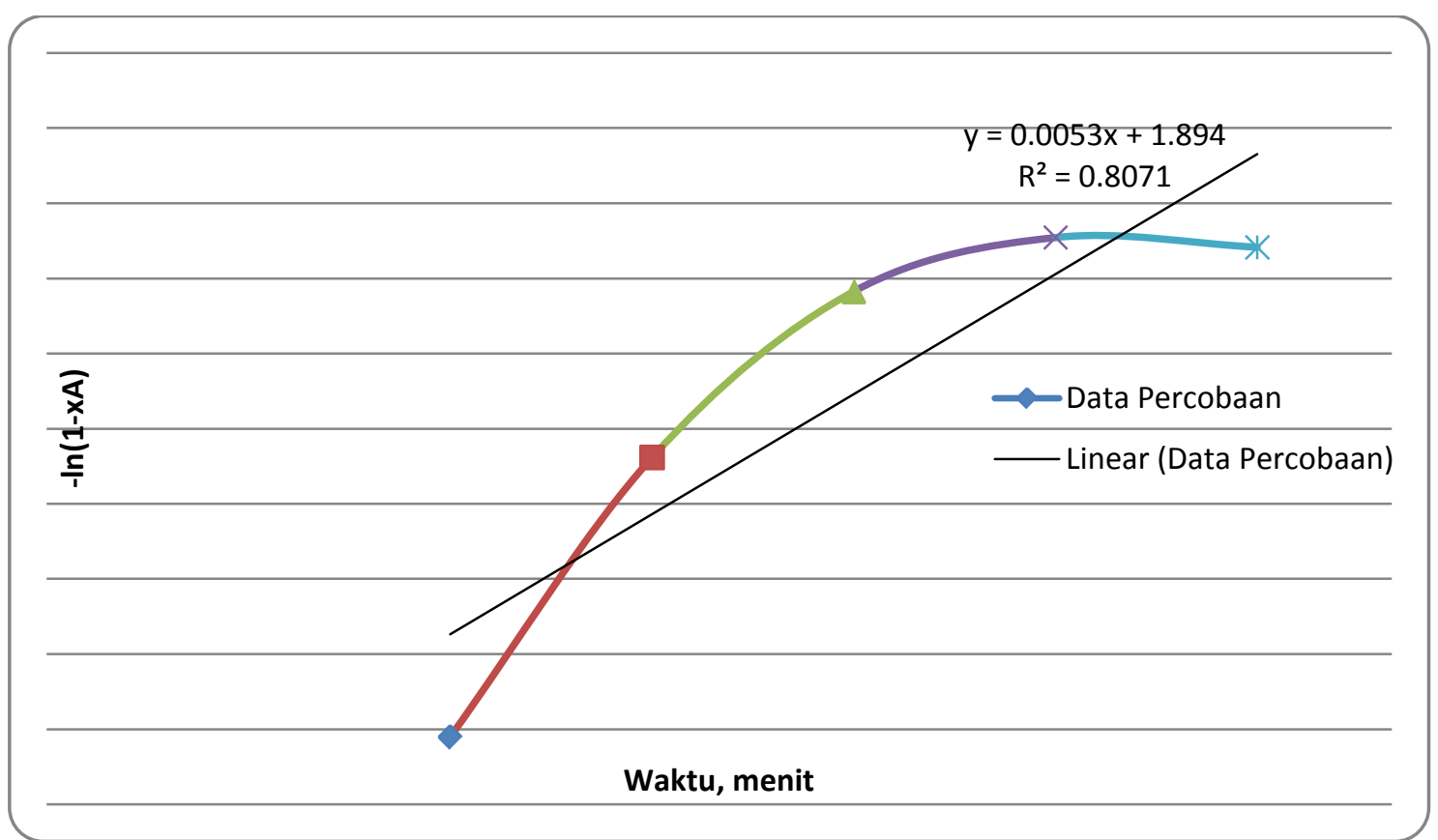

Gambar 1. Grafik hubungan waktu dan $-\ln (1-\mathrm{Xa})$

\section{b. Pengaruh suhu reaksi}

Pada penelitian dengan pengaruh suhu reaksi ini kondisi reaksi transesterifikasi dijalankan selama 60 menit dengan kecepatan putaran pengadukan $600 \mathrm{rpm}$, dan variasi suhu yaitu 40, 50 , 70 dan $90{ }^{\circ} \mathrm{C}$. Hasil variasi suhu reaksi terhadap konversi tertera pada pada tabel 4

Tabel 4. Hasil Biodiesel pada variasi suhu reaksi

\begin{tabular}{|l|c|c|c|c|}
\hline No. & $\begin{array}{c}\text { Variasi suhu } \\
\text { reaksi }\end{array}$ & $\begin{array}{c}\text { Konversi } \\
\text { Mol (\%) }\end{array}$ & $\ln (1-X a)$ & $\begin{array}{c}\mathrm{k} \\
\text { (menit }^{-1} \text { ) }\end{array}$ \\
\hline 1 & $40^{\circ} \mathrm{C}$ & 0,8781 & 2,105 & 0,120 \\
\hline 2 & $50^{\circ} \mathrm{C}$ & 0,8928 & 2,233 & 0,139 \\
\hline 3 & $70^{\circ} \mathrm{C}$ & 0,8995 & 2,2976 & 0,149 \\
\hline 4 & $90^{\circ} \mathrm{C}$ & 0,9293 & 2,6492 & 0,219 \\
\hline
\end{tabular}

Dari Tabel 4 diketahui bahwa laju reaksi (k) sebanding dengan meningkatnya suhu. Hal ini disebabkan semakin tinggi suhu, laju pergerakan setiap molekul akan semakin cepat, sehingga frekuensi tumbukan antar molekul akan meningkat dan reaksi menjadi semakin cepat. 


\section{c. Penentuan Nilai Parameter Kinetika Reaksi}

Data hubungan konversi sebagai fungsi suhu dan waktu dapat digunakan sebagai data untuk menentukan harga setiap parameter pada model kinetika yang diusulkan.

Kinetika reaksi transesterifikasi didekati dengan orde satu semu (metanol yang digunakan berlebih) :

$$
\frac{-d C_{A}}{d t}=k t
$$

dengan k mengikuti Persamaan Arrhenius sebagai berikut :

$$
k=A \exp \left(-\frac{E}{R T}\right)
$$

Linierisasi persamaan di atas :

$$
\ln k=\ln \mathrm{A}-\left(\frac{E}{R}\right) \frac{1}{T}
$$

Dengan data pada Tabel 5 diperoleh hasil seperti yang tercantum pada Tabel 5

Tabel 5 .Perhitungan parameter kinetika

\begin{tabular}{|c|c|c|c|c|c|c|}
\hline No. & $\begin{array}{c}\text { Variasi suhu } \\
\text { reaksi }\end{array}$ & $\begin{array}{c}\text { Konversi } \\
\text { Mol (\%) }\end{array}$ & $\begin{array}{c}\ln (1 \\
-X a)\end{array}$ & $\begin{array}{c}\mathrm{k} \\
\left(\text { menit }^{-1}\right)\end{array}$ & $\begin{array}{c}1 / \mathrm{T} \\
(1 / \text { Kelvin })\end{array}$ & $\ln \mathrm{k}$ \\
\hline 1 & $40{ }^{\circ} \mathrm{C}$ & 0,8781 & 2,105 & 0,120 & 0,003193 & $-2,11952$ \\
\hline 2 & $50{ }^{\circ} \mathrm{C}$ & 0,8928 & 2,233 & 0,139 & 0,003095 & $-1,9747$ \\
\hline 3 & $70{ }^{\circ} \mathrm{C}$ & 0,8995 & 2,2976 & 0,149 & 0,002914 & $-1,90269$ \\
\hline 4 & $90{ }^{\circ} \mathrm{C}$ & 0,9293 & 2,6492 & 0,219 & 0,002754 & $-1,5184$ \\
\hline
\end{tabular}

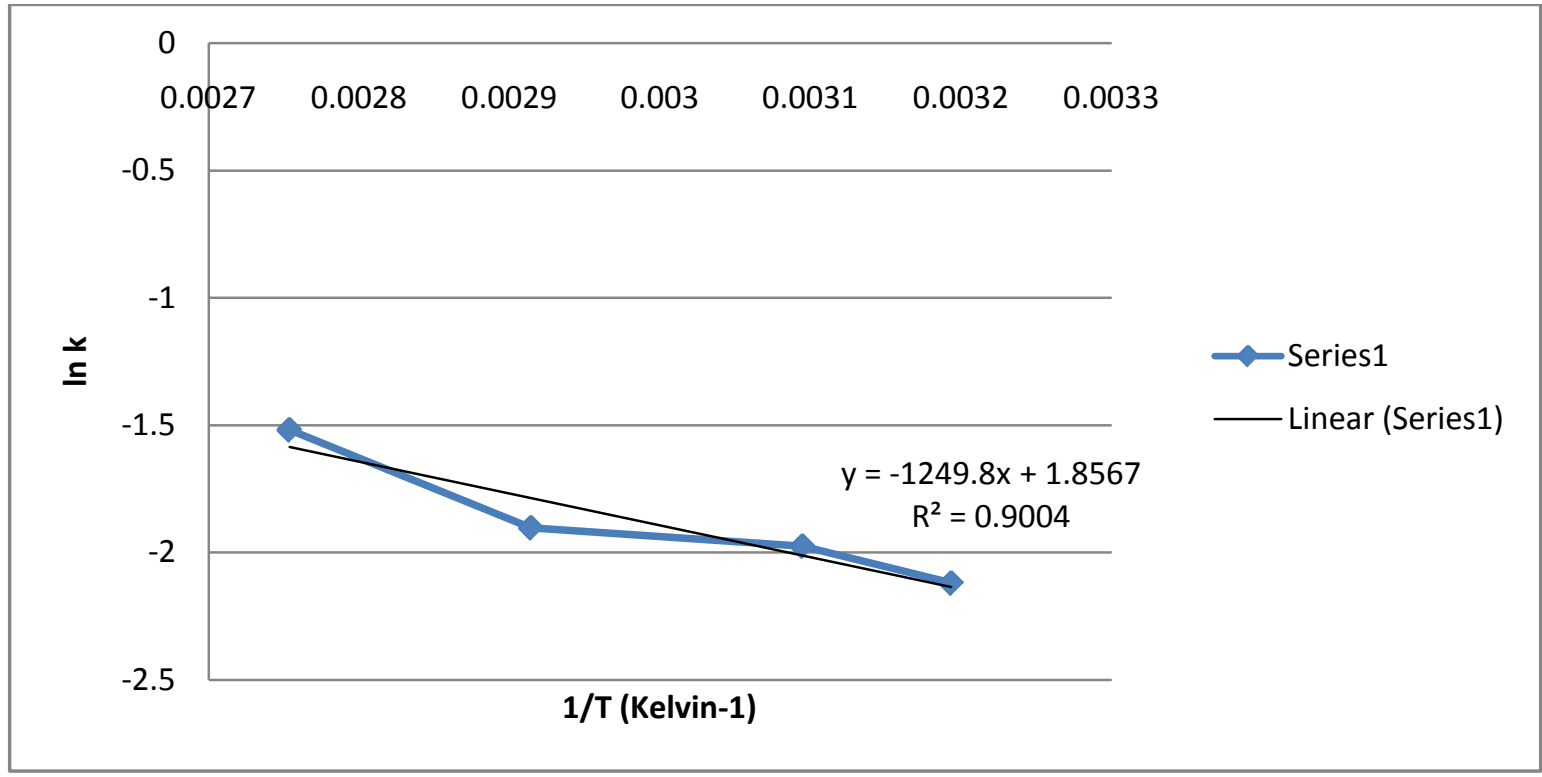

Gambar 2 Grafik hubungan 1/T dengan ln k 
Dari gambar 2 tersebut, diperoleh persamaan matematis sebagai berikut :

$$
\ln k=-1249\left(\frac{1}{T}\right)+1,856
$$

dengan mensubstitusi persamaan di atas pada persamaan sebelumnya, diperoleh nilai $\mathrm{E}=10390,84 \mathrm{~J} / \mathrm{mol}$ dan $\mathrm{A}=6.402573$.

\section{d. Hasil Analisis biodiesel.}

Biodiesel yang dihasilkan dianalisis di laboratorium Teknologi Minyak Bumi, Jurusan Teknik Kimia, Fakultas Teknik, dan laboratorium Kimia Fisika FMIPA Universitas Gadjah Mada. Hasil analisis ditunjukan pada tabel 5 berikut:

Tabel 6. Hasil Analissis Biodiesel dari Minyak Biji Kapuk

\begin{tabular}{|c|c|c|c|c|}
\hline No & Jenis Pemeriksaan & $\begin{array}{c}\text { Hasil } \\
\text { Pemeriksaan }\end{array}$ & $\begin{array}{c}\text { Standar Mutu } \\
\text { Biodiesel } \\
\text { RSNI EB 020551) }\end{array}$ & Metode \\
\hline 1. & $\begin{array}{c}\text { Specific Gravity at 60/60 }{ }^{0} \mathrm{~F} \\
\text { (RS }\end{array}$ & 0.8829 & $0.850-0.890$ & ASTM D 1298 \\
\hline 3. & $\begin{array}{c}\text { Viscosity Kinematic } \\
\text { at } 40^{0} \mathrm{C}, \mathrm{mm}^{2} / \mathrm{s}\end{array}$ & 4.112 & $2,3-6,0$ & ASTM D 445 \\
\hline 4 & Flash Point PM.cc, ${ }^{0} \mathrm{C}$ & 164.5 & min. 100 & ASTM D 93 \\
\hline
\end{tabular}

Hasil pengukuran kalor pembakaran / nilai kalor rata-rata = 9798,4 kalori/gram

Hasil analisis biodiesel dari minyak biji kapuk dan hasil pengukuran kalor pembakaran / nilai kalor biodiesel menunjukkkan bahwa nilai-nilai dari sifat fisis biodiesel yang dianalisa dan uji kalor telah memenuhi kriteria yang disyaratkan dalam acuan Standar Mutu Biodiesel Indonesia (RSNI EB 020551).

\section{Kesimpulan}

Dari penelitian yang telah dilakukan, dapat disimpulkan sebagai berikut. :

1. Reaksi transesterifikasi pada kondisi perbandingan mol minyak dan metanol 1:3 , dengan kecepatan putaran pengaduk $600 \mathrm{rpm}$ selama 105 menit dan suhu reaksi $90^{\circ} \mathrm{C}$ memberikan konversi tertinggi sebesar 0,916 mol (\%)

2. Reaksi transeterifikasi minyak biji kapuk menjadi biodiesel mengikuti reaksi orde 1 .

3. Hasil analisis biodiesel dan uji kalor biodiesel yang di dapat menunjukkan telah memenuhi kriteria yang disyaratkan dalam acuan Standar Mutu Biodiesel Indonesia (RSNI EB 020551).

\section{Ucapan Terimakasih}

Terimkasih kami sampaikan kepada Lembaga Penelitian dan Pengembangan (LPP) UAD yang telah membiayai penelitian ini dengan nomer kontrak : : M-87/LPP-UAD/III/2012. 


\section{Daftar Pustaka}

1. Prihandana, R., Hendroko, R., Nuramin, M., (2007), “Menghasilkan Biodiesel Murah”, PT. AgroMedia Pustaka, Jakarta.

2. TIMNAS BBN, (2008), "Bahan Bakar alternatif dari tumbuhan sebagai pengganti minyak bumimdan gas” Eka Cipta Fondation, penebar Swadaya, Jakarta .

3. Demirbas, A., (2008), "Studies on Cottonsedd oil Biodiesel prepare ini non catalytic SCF Condition”, Bioresaurce Technology, volume 99. Issue5, page 1125-1130

4. Linfeng, C., Guamin, X., (2007), “Tran Estherification of Cattonseed Oil to Biodiesel By using Heterogeneous Solid Basic Catalysts, Energi and Fuel ,21, page 3740 -3743

5. Salamah , S.(2011) “ Preparasi dan karakterisasi pembuatan biodiesel dari limbah industri kapuk” . laporan penelitian, Universitas Ahmad Dahlan Yogyakarta.

6. Sofiyah,dkk. (1996),” Kinetika Reaksi Etanolisis minyak biji kapuk dengan katalsi Natrium hidroksida dan penambahan garam Organik, Tesis , Pasca Sarjana UGM Yogyakarta.

7. Camara,L.T.D,Arnda,D.A.G (2011)” Reaction kinetic study of biodesel production from fatty Acid esterification with etanol” . I 7 EC Research, industry and Ennginering Chemistry rearch, 50, page $2544-2547$

8. Ramadhans, A.S., Mulareedharan, C., Jayaraj, S.,2005. “Performance and emission evaluation of diesel engine fueled with methyls esters of rubber seed oil. "Renewable Energy, 30, 1789-1800.

9. Rosu (1999), Rosu, Roxana., et al., (1999), “Enzymatic Synthesis of Symmetrical 1,3-Diacylglycerols by Direct Esterification of Glycerol in Solvent-Free System”, Nagoya University, Nagoya : Japan. 